\title{
LIMBA ROMÂNĂ CA LIMBĂ STRĂINĂ LA UNIVERSITATEA JOHANNES GUTENBERG-MAINZ
}

\author{
ANCA GÂŢĂ \\ Institutul Limbii Române din Bucureşti, \\ Facultatea de Litere, Universitatea „Dunărea de Jos” din Galaţi \\ Universitatea Johannes Gutenberg - Mainz
}

Rezumat. Limba română ca limbă străină este o disciplină academică a cărei predare în universități din lume se asociază adesea cu studiul culturii române, fie ca discipline independente, fie în mod integrat. Din 2013 până în prezent, la Universitatea Johannes Gutenberg din Mainz (JGUM), disciplinele Limba română ca limbă străină și Introducere în cultura română se predau studenților din domeniul filologic și din orice facultate a universității sau din universități partenere ale JGUM la nivel de licențăa, master, doctorat și post-doc, inclusiv studenți Erasmus prin intermediul activităților organizate de Lectoratul Institutului Limbii Române la Mainz. In formarea competențelor lingvistice de română ale cursanților, sunt aplicate principii tradiționale și recente ale didacticii limbilor străine, ale pragma-lingvisticii vizându-se performanțe lingvistice ale cursanților de nivel A2,B1-B2, C1, in conformitate cu Cadrul european de referință pentru limbi $(C E C R L)$ precum și competențe specifice de traducere.

Cuvinte-cheie: cheie: didactica limbilor străine, pragma-lingvistică, traducere, atelier didactic.

Abstract. Romanian as a foreign language is an academic subject the teaching of which in universities abroad is often associated to the study of Romanian culture either as independent subjects or integrated together. Since 2013 up to the present, at the Johannes Gutenberg University - Mainz (JGUM), the subjects Romanian as a foreign language and Introduction to the Romanian culture are available to students specializing mainly in Letters, Linguistics and History, as well as in any other academic field of the university or partner universities at bachelor, master, PhD and post-doc levels, including Erasmus students by means of the activities organised by the Romanian Language Institute Lectorate at the Romanisches Seminar of the JGUM. In forming and developing linguistic competences of Romanian, traditional and recent principles of foreign language methodology are applied, as well as those of pragma-linguistics while attempting at taking the students to the A2, B1B2, C1, levels of the CEFR (Common European Framework of Reference for Languages), as well as specific translation competences.

Keywords. foreign language teaching methodology, pragma-linguistics, translation, language workshop 


\section{Preambul istoric}

Limba română „,ca limbă străină” în universități din lume este o disciplină academică a cărei predare este asigurată și promovată de Guvernul României, prin intermediul Ministerului Educației și Ministerului Afacerilor Externe, activitățile academice și de promovare fiind administrate logistic și științific de către Institutul Limbii Române din București care coordonează Corpul Lectorilor români în străinătate ${ }^{1}$.

În urmă cu cincizeci de ani, la Seminarul de romanistică al Universității Johannes Gutenberg din Mainz (JGUM), profesorul de filologie romanică Wilhelm Theodor Elwert, cu studii la Lausanne, München și Freiburg im Breisgau, fost lector de filologie romanică la Universitatea din Pisa, a stârnit și alimentat interesul comunității academice de la JGUM pentru limba și cultura română, organizând primele evenimente de promovare a limbii şi culturii româneşti, precum şi activităţi de predare ale acestora. Ulterior, Dr. Gerhard Damblemont, lector de literatură franceză la Roma, se implică în aceste activități, dedicând o mare parte din preocupările sale academice acestei colaborări și constituindu-și o uriașă bibliotecă de literatură și cultură românească $\breve{2}^{2}$ amplu promovată în reuniunile academice curente de la Mainz. De asemenea, Gerhard Damblemont publică articole despre scriitori români și opera acestora. În anii optzeci și nouăzeci, predau cursuri de limbă şi cultură românească dr. Augustin Alexandru Bidian, de formație filosof și iubitor de cultură românească şi dr. Gerhardt Csejka cu studii de germanistică și romanistică, scriitor, și unul dintre cei mai activi traducători de literatură română în limba germană .

În acest fel s-a construit tradiția studiului limbii și culturii române la JGUM, dar poate nu ar fi existat azi aici un lectorat, fondat în 2013 fără eforturile susținute ale Institutului Limbii Române din București (ILR), alături de Ambasada României la Berlin și dăruirea a trei membri de elită ai corpului academic de la JGUM, Dr. Wolf Lustig, directorul academic al Seminarului de Romanistică (2000-2017), vorbitor a douăsprezece limbi, între care și româna, Prof. dr. Hans Christian Maner (din 2006), de la Departamentul de istorie, specialist în istorie est-europeană și românească, și coordonator, din 2009, al filialei din Mainz a Societăţii sud-est europene (Zweigstelle Mainz der Südosteuropa-Gesellschaft), care organizează evenimente legate de culturile

${ }^{1}$ https://www.ilr.ro/category/lectorate/corpul-lectorilor/

2 După decesul domnului Damblemont, în 2014, familia a donat integral biblioteca de carte românească universității din Mainz, donaţie preluată de Dr. Wolf Lustig. Am prelucrat personal această donație pentru a fi inventariată de serviciile bibliotecii universitare e la JGUM în anii 2016-2017. Aceste volume se regăsesc azi pe rafturile bibliotecii campusului din Mainz și sunt accesibile prin împrumut interbibliotecar și studenților de la Facultatea de traduceri din Germersheim sau din alte universități.

${ }^{3}$ O prezentare detaliată a activității Lectoratului ILR de la JGUM este disponibilă în acces liber în volumul editat cu ocazia Congresului internațional aniversar a 20 de ani de existență ILR „Douăzeci de ani de tradiție și internaționalizare”, septembrie 2019. (Cuibus și Ivancu, 2019, pp. 94-98) http://www.ilr.ro/wp-content/uploads/2019/11/ VOLUM-INSTITUTUL-LIMBII-ROMANE_20-de-ani_2019-1.pdf 
din spaţiul de limbă română. Profesorul Maner întreține relații de colaborare și schimburi academice cu numeroase universități din România și Institutele de istorie ale Academiei române, organizând anual o excursie de studii în România pentru viitorii istorici. Acestora li s-a alăturat Prof. dr. Sylvia Thiele, specializată în didactica limbilor romanice, care, a avut în responsabilitatea academică activitatea lectoratului ILR, atât ca decan, în perioada 2018-2020, cât și ca director al Seminarului de romanistică în 2020-2021, continuând azi această implicare, ca specialist în didactica limbilor și coordonator al unor proiecte transeuropene de formare multilingvă $\breve{4}^{4}$. Lectoratul ILR a fost și este cadrul în care și-au desfășurat activitatea până în prezent trei lectori de limbă și cultură română ${ }^{5}$.

\section{Oferta didactică a Lectoratului ILR la Universitatea Johannes Gutenberg din Mainz}

1.1. Predare

Activitatea didactică solicitată de Seminarul de romanistică, JGUM, este reprezentată prin următoarele componente, de regulă, identice pentru semestrele 1 şi 2 : săptămână

Limba română pentru începători A1-A2 - Curs practic (exerciţii), 2 ore/

Limba română pentru avansaţi A2-B1 - Curs practic (exerciţii), 2 ore/ săptămână

Introducere în cultura română - Prelegere interactivă, 2 ore/săptămână

Lecturi româneşti şi traduceri B1-C1 Curs -practic (exerciţii), 2 ore/ săptămână

Aceste activităţi sunt prevăzute ca facultative sau opţionale, în funcţie de alegerea studenţilor, după cum urmează:

- Regim facultativ:

- Auditor liber (Hörer), cu frecventarea activităţilor conform propriului program academic şi profesional şi propriului parcurs didactic;

- Auditor liber (Hörer), cu frecventarea activităţilor conform propriului program academic şi profesional şi propriului parcurs didactic, cu evaluare finală cu un calificativ de tip admis/respins; în acest caz, studentul are obligaţia de a studia o limbă străină, alegând, de regulă, unul dintre cursurile practice (exerciţii) de limbă română, conform nivelului său de competenţă lingvistică.

${ }^{4}$ Dintre cele mai recente, face parte proiectul FORTHEM, cf. https://www.forthemalliance.eu/fit-forthem/, la care este asociat și lectoratul ILR. A se vedea și https://www. forthem-alliance.eu/objectives/labs/multilingualism-in-school-and-higher-education/

5 Dr. Ioana Maria Şarcă (2013-2014), lector universitar la Universitatea din Oradea, Dr. Cătălin Constantinescu (2014-2016), conferenţiar universitar la Universitatea „Alexandru Ioan Cuza” din Iaşi. Dr. Anca Gâţă $(2016$ - 2021/22), profesor universitar la Universitatea „Dunărea de Jos” din Galaţi. 
- Regim opţional: student, cu frecventarea activităţilor conform propriului parcurs didactic, cu evaluare finală cu notă consemnată în registrul matricol. În acest caz, studentul are obligaţia de a urma un „modulul de limbă şi cultură română”. Studenţii pot urma concomitent sau succesiv (pe parcursul a 2-3 semestre) activităţile didactice din cadrul acestui modul. De regulă, modulul este ales ca Replacement module (Ersatz Modul) de către studenţii din domeniul ştiinţelor socio-umane, care, din motive personale sau profesionale, nu pot efectua un stagiu semestrial Erasmus în străinătate. Modulul este compus din:

○ unul dintre cursurile practice (exerciţii) de limbă română sau ambele, conform nivelului de competenţă lingvistică al cursantului;

- cursul de Introducere în cultura română.

Perioadele de predare variază între 10 și 16 săptămâni pe semestru.

\subsection{Fişe de lucru şi materiale auxiliare pentru cursurile de limbă (LRLS)}

În vederea activităţilor desfăşurate la cele trei activităţi didactice de limbă română pe parcursul celor șase semestre, se folosesc fişe de lucru, adecvate nivelului de competenţă lingvistică vizat şi diverselor subcompetenţe de comunicare, realizate în acest scop din perspectiva didacticii limbilor străine, și modificate și actualizate continuu, conform receptării acestora de către cursanți. Sunt folosite ca punct de plecare, în acest scop, materiale personale anterior realizate şi materiale de referinţă în domeniul limbii române ca limbă străină. Sunt avute în vedere principii de didactică a limbilor străine şi recomandări din Cadrul european de referinţă pentru limbi străine. Pentru elaborarea fișelor, se folosește formatul standard (A4) atât în vederea unei manipulări didactice uşoare (imprimare, scanare, editare ulterioară), cât şi pentru a da cursantului posibilitatea de a completa şi de a utiliza fişele individuale în activităţile din afara clasei.

În vederea utilizării unei game largi de materiale didactice auxiliare, a fost compilată o listă de categorii v. mai jos) pe baza bibliografiei recente din domeniu, a fost realizată o selecţie de imagini şi documente autentice, au fost selectate secvenţe de interacțiuni pe suport video sau audio şi adaptate documente autentice (formulare, informaţii turistice, meniuri), pentru o mai bună receptare conform nivelului de studiu (cf. și Beacco, 2007):

Imprimate scrise şi/sau ilustrate (Formulare, reclame, oferte, prospecte, calendare, orare, program institutii / birouri, facturi, meniuri, bilete de transport, reviste, ziare, reţete de bucate, instrucţiuni, anunţuri publicitare şi de mică publicitate, felicitări pentru diverse ocazii, arbore genealogic. Fragmente literare. Imagini, fotografi, timbre: anotimpuri, forme de relief, aşezări, clădiri, profesii, persoane etc. Benzi desenate.). Documente audio autentice sau simulate didactic (Mesagerie de voce, 
fragmente emisiuni radiofonice, anunţuri aeroport / gară, publicitate radio, muzică.) Documente video (Fragmente filme, emisiuni televiziune, desene animate, reclame TV). Documente virtuale (Website-uri, bloguri, publicitate virtuală. Imagini culori.) Realia (Obiecte uzuale disponibile in mediul de formare și/sau special integrate în activitățile didactice: mobilier, birotică, monede, bancnote, instrumente, hărţi etc.)

Fişele de lucru realizate exploatează concepte metodice şi didactice recurente tradiţionale și recente în domeniul predării-învăţării limbilor străine. Având în vedere un nivel de competenţă lingvistică A.1, de la care pornește demersul didactic, se urmărește, în special, familiarizarea studenţilor cu elemente accesibile de vocabular şi culturale, care pot fi relativ frecvent întâlnite în context românesc, în vederea atingerii unor performanţe lingvistice de tip A.2 / B.2 şi formării unui statut al cursantului de utilizator independent al limbii.

Pe lângă alte domenii lexicale abordate în contextul prezentat, câmpul lexical al obiectelor de îmbrăcăminte reprezintă una dintre zonele investigate și explorate din punct de vedere didactic pentru a crea activitătii diverse de dezvoltare a competențelor lingvistice. Tematica vestimentară este interesantă și atractivă (cf. Gâță 2019, p. 255) deoarece abordarea didactică se poate face din perspectivă multiculturală, valorificându-se cunoștințele generale și enciclopedice ale cursanților precum și articolele de vestimentație disponibile ad-hoc (Realia, sau simulate, a se vedea mai sus), diferite de la o cultură la alta, fiind utile intersectările între (sub)câmpurile lexicale, precum cele corespunzând accesoriilor vestimentare, anotimpurilor, localizărilor geografice, țesăturilor, materiilor de bază, culorilor, precum și având în vedere dimensiunea interactivă, cooperativă a abordărilor dialogale în contextul exploatării acestui vocabular cu dezvoltarea unor competențe pragmatice prin care se activează tipare și structuri sintactice uzuale
ex. nivel B2
Ce bluză îți place mai mult? Cea verde sau cea roșie? Ce geantă cumperi? Pe cea din piele sau pe cea din piele sintetică?

Preiau mai jos, spre exemplificare, o parte din constatările și activitățile create, prezentate într-un articol anterior. Textele sau dialogurile integrate în activități de formare, exersare şi dezvoltare a deprinderilor lingvistice sunt create prin simularea unor interacțiuni, încercându-se, pe cât posibil, și realizarea / înregistrărilor audio corespunzătoare pentru a le pune la dispoziția cursanților (Gâță 2019, p. 268-271 ff.):

1. Ascultați textul. Lucrați în echipă și alegeți din plicuri imaginile corespunzătoare. Citiți textul:

\section{Mirela pleacă în vacanță la niște prieteni}

Mirela: E vară și nu e frig, dar iau / pot lua multe haine pentru că merg cu autocarul. Asta e lista: trei bluze, două fuste, o jachetă, un pulover, o vestă 
veche, două perechi de blugi, o pereche de pantaloni scurți, o pereche de cizme, una de pantofi, niște adidași, șase perechi de șosete, niște ciorapi pentru cizme, două costume de baie, o poșetă și o umbrelă. E vreme bună, iar dacă plouă, cizmele și vesta sunt comode.

2. Intrebați colega / colegul completând spațiile cu cuvintele lipsă. Răspundeți la întrebări. Alegeți adjective la forma potrivită. Folosiți toate adjectivele. Un răspuns nu are nevoie de adjectiv.

alb - albă - galbenă - negre - roșie - roșii - verde

Ce culoare e jacheta? - Jacheta e

culoare e puloverul? -

$\overline{\mathrm{Ce}}$ sunt bluzele? - Una e e , una $\mathrm{e}$ şi una e sunt cizmele? -

sunt - $\longrightarrow$ sunt pantalonii scurți? sunt

clasici - comozi - veche - ???

Ce vestă ia Mirela? - Ia o vestă

Cum sunt blugii? -

Ce fel sunt pantofii? sunt

Ce marcă sunt adidașii? sunt sunt marca

De asemenea, definiția didactică - uneori imperfectă din punct de vedere lexicografic, fie pentru că e simplificată, fie pentru că se preferă o anumită perspectivă asupra termenului / obiectului definit - poate constitui un suport adecvat pentru formarea și dezvoltarea competențelor lingvistice. Abordarea definiției didactice mi-a permis, în contextul studiului asupra lexicului vestimentar (Gâță, 2019) elaborarea / unei „legi” / unui „principiu” de didactică a lexicului: În scopul predării-învățării unitătilor lexicale care aparțin unui anumit (sub)domeniu ontologic, se identifică un obiect reprezentativ pentru respectivul domeniu, a cărui „etichetă" lingvistică se prezintă în mod unitar alături de unităţile lexicale corespunzătoare elementelor structurale ale obiectului reprezentativ identificat pentru domeniul în cauză, de exemplu, cămaşă / bluză și meronimele corespunzătoare, respectiv, mânecă lungă / scurtă, nasture, guler, precum și hiperonimul haină / îmbrăcăminte, chiar dacă acesta prezintă o polisemie care poate fi discutată într-o etapă ulterioară sau la un nivel superior. Adaptarea definiției lexicografice, folosind uneori mai multe surse este esențială, definiția de dicționar nefiind totdeauna pertinentă din punct de vedere didactic.

Materialele create pot fi exploatate și în predarea limbii române ca a doua limbă sau pentru alofoni (cazul Republicii Moldova, în special în Regiunea autonomă Găgăuzia). 


\section{Cultura română}

Pentru cursul de Introducere în cultura română (Prelegeri interactive, 2 ore/săptămână) prezentările Powerpoint sunt ilustrate cu imagini (fotografii, hărţi) şi îmbogăţite cu hyperlink-uri la documente video şi audio cu specific cultural (extrase din concerte, spectacole, filme artistice, interviuri, documentare etc.). Se utilizează un material auxiliar reprezentat de reviste, albume de artă, monografii de cultură şi civilizaţie. Prezentările sunt organizate pe principii tematice și interconexiuni și relaționate, astfel încât într-o prezentare / curs sunt transmise informații cu privire la geografie, istorie, economie, literatură, muzică, arte plastice, turism etc.

\section{Lectoratul digital}

În perioada aprilie 2020 - octombrie 2021, în contextul pandemic, lectoratul a funcționat în regim / mediul digital, atât pentru activitățile de predare, cât și pentru cele de îndrumare, consultații, comunicare curentă cu studenții și personalul administrativ, nemaiexistând acces, pentru studenți, decât la bibliotecă.

În ciuda tuturor provocărilor și aspectelor negative ale desfășurării activității academice în mediul digital, a existat un beneficiu, în ce privește Lectoratul de la Mainz, anume disponibilitatea cursurilor pentru studenții din al doilea campus al JGUM, de la Germersheim, unde se află Facultatea de Traduceri, la aproximativ $100 \mathrm{~km}$ de Mainz. Aceștia nu puteau participa în mod normal la cursurile oferite in praesentia. Pe baza deprinderilor de folosire a platformelor digitale create în contextul pandemic, va fi menținut în semestrele următoare un curs suplimentar de limbă la nivel începător în regim digital pentru studenții în domeniul traducerilor și limbilor moderne aplicate, extrem de interesați în a-și lărgi paleta de competențe și având și o mare disponibilitate pentru a învăța limbi străine și un sistem de lucru care îi ajută să atingă performanțe rapid și să-și însușească competențele de comunicare de bază în limba română.

A existat aceeași parte bună a digitalizării forțate și pentru studenții Erasmus care au avut dificultăţi în a se înscrie la alte cursuri, idem pentru cei înscriși regulat la JGUM și aflați teoretic în stagiu Erasmus, putând continua cursurile la universitatea de origine chiar fără credite, în regim facultativ, pentru a continua să își îmbunătățească performanțele.

În aceleași cadre a fost mult mai simplă participarea invitaților la cursurile de cultură, în vederea diversificării acestora. Invitaţi au fost colegi din universitatea mea de proveniență și colegi lectori ILR din alte universități din străinătate cu teme care au completat lista celor disponibile la Mainz pe care apoi le-am putut interconecta cu temele uzuale programate . E o practică care va fi menținută în continuare și, pe baza unui proiect în curs de dezvoltare o vom extinde și la cursurile de limbă, nu numai la cele de cultură. Dintre temele prezentate de invitați:

Prof. dr. Constantin Ardeleanu, Universitatea „Dunărea de Jos din Galați” - 


\section{Dunărea de Jos între imperii - formarea națiunii române}

Geopolitică, economie și ecologie la Dunărea de Jos Galați”

Lect. dr. Oana Celia Gheorghiu, Universitatea „Dunărea de Jos din

Perspective anecdotice asupra comunismului românesc: povestiri din Epoca de Aur

Dr. Florin Cioban, Lectorat ILR, Universitatea Eötvös Loránd, Budapesta

Tradiții de iarnă în cultura română

Dr. Nicolae Stanciu, Lectorat ILR, Universitatea din Skopje

Eroi mitici în culturile balcanice

Dr. Silvia Irina Zimmermann, Centrul de cercetări Carmen Sylva, Arhiva princiară de la Neuwied

Priect de editare: Corespondența cuplului regal Carol I și Elisabeta de România cu Prințul Karl Anton von Hohenzollern-Sigmaringen din Arhivele Nașionale, București (1866-1885)

Dr. Ovidiu Ivancu, Lectorat ILR, Universitatea din Vilnius

Cultura română în mișcare de la est spre vest. O scurtă istorie a ideilor. Scriitor, editor și redactor Marian Coman, Editura Nemira, București

Un interviu despre ficțiune

Dr. Oana Uță-Bărbulescu, Lectorat ILR, Universitatea din Oxford

Limba română între limbile romanice

Dr. Romanița Constantinescu, Lectorat ILR, Universitatea din Heidelberg Stema Principatelor Unite ale României (1859-1866)

\section{Marketing cultural și lingvistic}

Pornind de la principiul că cel mai bun marketing al unui curs este reprezentat de modalităţile efective de derulare a acestuia, pe parcursul activităţilor didactice au fost vizate, în măsura timpului alocat și posibilităţilor logistice, dezideratele diverse ale cursanţilor: aceştia doresc, în mod distinct şi în măsuri diferite, conversaţie uzuală, gramatică, exprimare în scris, lexic tematic, audiţie, teme, materiale de lectură, bibliografie suplimentară. Având în vedere numărul limitat de ore, specificul limbii române, statutul de auditor liber al unora dintre studenţi, precum şi frecventarea unor cursuri de către colegi de la Seminarul de romanistică, sarcinile didactice sunt combinate și diversificate, diferind de la un semestru la altul.

Materialele şi suporturile didactice oferite de ILR constituie Biblioteca Lectoratului și permit această diversificare, precum și concepția de materiale didactice şi auxiliare proprii utilizate în demersul pedagogic.

O importantă contribuție la promovarea Lectoratului o au acțiunile extracurriculare precum serile culturale sau atelierele tematice. Din păcate, ca în multe alte domenii, consecințele pandemiei pe care le trăim încă, s-au regăsit în dispariția serilor culturale în cadrul cărora participanții la cursuri contribuiau cu propriile prezentări și intervenții la fixarea și diseminarea cunoștințelor despre cultura română. Î̉n contextul desfășurării tuturor activităţilor didactice în regim digital în ultimele trei semestre a fost imposibilă realizarea acestor evenimente în același regim, studenții fiind suprasolicitați. Am reuşit să 
păstrăm, în al doilea semestru digital, atelierul de traduceri și cel de teatru, urmând să fie reluate tot în sistem digital.

Studientag Rumänien este un eveniment anual organizat de Departamentul de istorie est-europeană în colaborare cu Lectoratul ILR:

- Editia a treia (2015): Räume und Menschen in Geschichte, Literatur und Politik Rumäniens (19-21 Jahrhundert) - Spații și oameni în istoria, literatura și politica României (secolele XIX-XX'I)

- Editia a patra (2016): Traditionelle Volkskultur in Literatur und Film - Cultura populară tradițională în literatură și film

- Ediția a cincea (2017): Rumänien und EUropa. Blick nach vorne mit oder ohne Erinnerung? Privind înainte cu sau fără amintiri?

- Ediția a șasea (2018): Erster Weltkrieg und die kulturellen Folgen vergleichende und regionale Perspektiven - Primul război mondial și urmările sale culturale - perspective comparative și regionale comunicare personală cu privire la opera lui Camil Petrescu.

- Ediția a șaptea (2019): Migration - Heimat - Identität. Migrație Locuri de origine - identitate

- Editia a opta (2020): Die Moldau. Zwischen Imperien und Kulturräumen - Moldova.Între imperii și spații culturale

- Editia a noua (2021): „Die Minderheit der Roma - Geschichte(n) zwischen Ausgrenzung und Anerkennung" - Minoritatea romă Istorie / istorisiri între excluziune socială și recunoaștere

\section{Referințe bibliografice:}

1. Beacco Jean-Claude. L'approche par compétences dans l'enseignement des langues. Paris: Didier, 2007.

2. Cuibus, Daiana și Ivancu, Emilia (ed.). ILR - 20 de ani de tradiție și internaționalizare. București / Craiova: Sitech, 2019. Disponibil: http:/www.ilr.ro/ wp-content/uploads/2019/11/VOLUM-INSTITUTUL-LIMBII-ROMANE_20-deani_2019-1.pdf

3. Gâță, Anca.Le champ lexical de l'habillement dans l'enseignementapprentissage du roumain langue étrangère. În Mélanges francophones, Annales de l'Université „Dunărea de Jos” de Galaţi, Fascicule XXIII Numéro 17/Volume XIV, „Regards croisés sur le code vestimentaire: des pratiques sociolinguistiques aux représentations littéraires", Drăgoi, Mirela și Ganea, Alina (ed.), p. 255-271. 